\title{
Mechanistic-empirical pavement design guide (MEPDG): a bird's-eye view
}

\author{
Qiang $\mathrm{LI}^{1 *}$, Danny X. XIAO ${ }^{2}$, Kelvin C. P. WANG ${ }^{2}$, Kevin D. HALL ${ }^{2}$, Yanjun QIU $^{3}$ \\ 1. Department of Civil and Environmental Engineering, University of Delaware, Newark, DE 19711, USA \\ 2. Department of Civil Engineering, University of Arkansas, Fayetteville, AR 72701, USA \\ 3. School of Civil Engineering, Southwest Jiaotong University, Chengdu 610031, China
}

\begin{abstract}
Past editions of the American Association of State Highway and Transportation Officials (AASHTO) Guide for Design of Pavement Structures have served well for several decades; nevertheless, many serious limitations exist for their continued use as the nation's primary pavement design procedures. Researchers are now incorporating the latest advances in pavement design into the new Mechanistic-Empirical Pavement Design Guide (MEPDG), developed under the National Cooperative Highway Research Program (NCHRP) 1-37A project and adopted and published by AASHTO. The MEPDG procedure offers several dramatic improvements over the current pavement design guide and presents a new paradigm in the way pavement design is performed. However, MEPDG is substantially more complex than the AASHTO Design Guide by considering the input parameters that influence pavement performance, including traffic, climate, pavement structure and material properties, and applying the principles of engineering mechanics to predict critical pavement responses. It requires significantly more input from the designer. Some of the required data are either not tracked previously or are stored in locations not familiar to designers, and many data sets need to be preprocessed for use in the MEPDG. As a result, tremendous research work has been conducted and still more challenges need to be tackled both in federal and state levels for the full implementation of MEPDG. This paper, for the first time, provides a comprehensive bird's eye view for the MEPDG procedure, including the evolvement of the design methodology, an overview of the design philosophy and its components, the research conducted during the development, improvement, and implementation phases, and the challenges remained and future developments directions. It is anticipated that the efforts in this paper aid in enhancing the mechanistic-empirical based pavement design for future continuous improvement to keep up with changes in trucking, materials, construction, design concepts, computers, and so on.
\end{abstract}

Key words: design of pavement structures; mechanistic-empirical pavement design guide (MEPDG); local calibration; implementation challenges

(C) 2011 JMT. All rights reserved.

\section{Introduction}

$\mathrm{T}$ he American Association of State Highway Officials (AASHO) Road Test was a milestone for engineers to understand how pavements perform, based on which the current American Association of State Highway and Transportation Officials (AASHTO) pavement design procedures were developed. However, these design procedures are insufficient for the traffic, materials and construction techniques today since the empirical equations in nature were derived from the Road Test in a single geographic location, one type of subgrade, one hot mix asphalt mixture and one Portland cement con-

Received May 4, 2011; revision accepted Jun. 7, 2011

*Corresponding author. Tel.:+1-302-831-7002

E-mail: qli@udel.edu (Q. LI)

doi: 10.3969/j.issn.2095-087X.2011.02.007 crete mixture, two unbound base, and under slightly over 1 million axle load applications [1].

It is until now, a half century after the Road Test, that pavement design is updating from empirical method to mechanistic-empirical method. Developed under the National Cooperative Highway Research Program (NCHRP), the Mechanistic-Empirical Pavement Design Guide (MEPDG) presents a new paradigm for pavement design and analysis. The Guide considers input parameters that influence pavement performance, including traffic, climate, and pavement structure and material properties, and applies the principles of engineering mechanics to predict critical pavement responses [1]. Incorporating hundreds of new variables, new parameters to characterize materials and the complexity of the implementation, MEPDG presents many research tasks and challenges for the pavement community.

Since the AASHTO Joint Task Force on Pavement (JTFOP) initiated the MEPDG development efforts, 
numerous research projects related to MEPDG have been conducted. Although a wide range of topics have been investigated and findings have been disseminated by reports, papers and presentations, there is no paper comprehensive study cataloging these research achievements. This paper is intends to fill this gap. The outline of the paper comes as follows. First, the history of pavement design methods is reviewed, followed by a brief introduction of MEPDG and its components. Second, the art-of-state research conducted during the development, improvement, and implementation phases of MEPDG are explored and analyzed. Finally challenges and future developments are presented.

\section{Evolvement of pavement design in U.S.}

The empirical based and the mechanistic-empirical based pavement structural design approaches are the two principal methods widely studied and used in the United States today.

\subsection{Empirical method: AASHTO pavement design method}

Many pavement design procedures adopt an empirical approach. The relationships among design inputs, such as loads, materials, layer configurations and environment, and pavement failure were obtained through engineering experience, experimental observations, or a combination of both.

The American Association of State Highway and Transportation Officials (AASHTO) Guide for Design of Pavement Structures [2] is the primary document used to design new and rehabilitated highway pavements in the United States today. The Federal Highway Administration's (FHWA) 1995-1997 National Pavement Design Review found that more than $80 \%$ of states use the 1972, 1986, or 1993 AASHTO Guides [3]. All versions of the AASHTO design guide are based on empirical models drawn from field performance data measured at the AASHO road test in the late 1950s located at just northwest of Ottawa, Illinois, about 80 miles southwest of Chicago, along with some theoretical support for layer coefficients and drainage factors. The overall serviceability of the pavement is quantified by the present serviceability index (PSI), a composite performance measure combining cracking, patching, rutting, and other distresses. Roughness is the dominant factor governing PSI and is therefore the principal component of pavement performance measure.

The various versions of the AASHTO guide have served the industry well, but have deficiencies due to some of the limitations of the AASHO Road Test [1]:
(1) Today's traffic loads are much higher than they were six decades ago;

(2) Rehabilitated pavements were not monitored;

(3) Only one climatic condition and one subgrade type were included in the road test;

(4) Only one hot-mix asphalt and one PCC mixture were studied;

(5) Test pavements did not include drainage;

(6) Only 2 years of monitoring were conducted, rather than the entire pavement life of every section (some sections did, however, fail within 2 years).

\subsection{The mechanistic-empirical pavement design guide (MEPDG)}

\subsubsection{National cooperative highway research program (NCHRP) project 1-26}

Right after the development of the 1986 AASHTO Design Guide, the need to develop mechanistic pavement analysis and design procedures suitable for use in future versions of the AASHTO guide was initiated by AASHTO. NCHRP Project 1-26, Calibrated Mechanistic Structural Analysis Procedures for Pavements, aimed at providing the basic framework for future development of a mechanisticempirical (M-E) pavement design method [4].

In pavement design, the responses can be the stresses, strains and deflections within a pavement structure, and the physical causes are the loads (both environmental and traffic) and material properties of the pavement structure. The relationships among these phenomena and their physical causes are typically described using mathematical models. Along with this mechanistic approach, empirical models are used when defining the relationships among the calculated stresses, strains and deflections, and pavement failure. As a result, the number of loading cycles to failure can be derived. This approach is called a mechanistic empirical based design method.

Since NCHRP 1-26 was completed, several typical mechanistic-empirical based design approaches were developed, including the 2002 AASHTO MechanisticEmpirical Design Guide (MEPDG) [1], the Washington State Department of Transportation (WSDOT) Pavement Guide [5], and the MnPAVE computer program adopted in Minnesota Department of Transportation (MN/DOT) [6].

\subsubsection{The long term pavement performance (LTPP) program}

Supported by the Congress, the LTPP program started in 1987, as part of the Strategic Highway Research Program (SHRP). Over a span of 20 years, the LTPP program has monitored the performance of nearly 
2500 in-service pavement test sections throughout the United States and Canada representing the wide range of climatic and soil conditions on the continent. With pavement performance over time, researchers are gaining insight into how and why they perform as they do, which provides valuable lessons on how to build better, longer lasting, more cost effective pavements.

An original LTPP objective was to acquire data for use in evaluating existing design methods and in developing new ones. The Development of MEPDG required detailed information about pavements located across the country and representing a wide range of loading, climate, and subgrade conditions with varying structural compositions. The LTPP database provided such long-term performance data for hundreds of asphalt, concrete, and rehabilitated pavement sections that were used in the national calibration. In fact, the MEPDG could not have been completed without the type and national extent of data provided by the LTPP studies [7]. All of the traffic loading defaults provided in the MEPDG, for example, were derived from the LTPP traffic database using weigh-in-motion (WIM) sites across the United States and Canada, and all of the distress and smoothness models in the MEPDG were calibrated using LTPP data. In addition, LTPP data is invaluable to each State highway agency for its own local validation and calibration purposes. The distribution of the LTPP pavement test sections is shown in Fig. 1 [7].

\subsubsection{The mechanistic-empirical pavement design guide (MEPDG)}

The Mechanistic-Empirical Design Guide for New and Rehabilitated Pavement Structures [1], known as MEPDG, was released in 2004 under the NCHRP Project 1-37A. MEPDG provides significant potential benefits over the 1993 AASHTO Guide. This approach provides more realistic characterization of in-service pavements and provides uniform guidelines for designing the in-common features of flexible, rigid, and composite pavements. It also offers procedures for evaluating existing pavements and recommendations for rehabilitation treatments, drainage, and foundation improvements. Most importantly, its computational software: (1) implements an integrated analysis approach for predicting pavement condition over time (including fatigue, rutting, and thermal cracking in asphalt pavements, and cracking and faulting in concrete pavements) that accounts for the interaction of traffic, climate, and pavement structure; (2) allows consideration of special loadings with multiple tires or axles; and (3) provides a means for evaluating design variability and reliability. MEPDG allows pavement designers to make better informed decisions and take cost-effective advantage of new materials and features. The software can also serve as a forensic tool for analyzing the condition of existing pavements and pinpointing deficiencies in past designs.

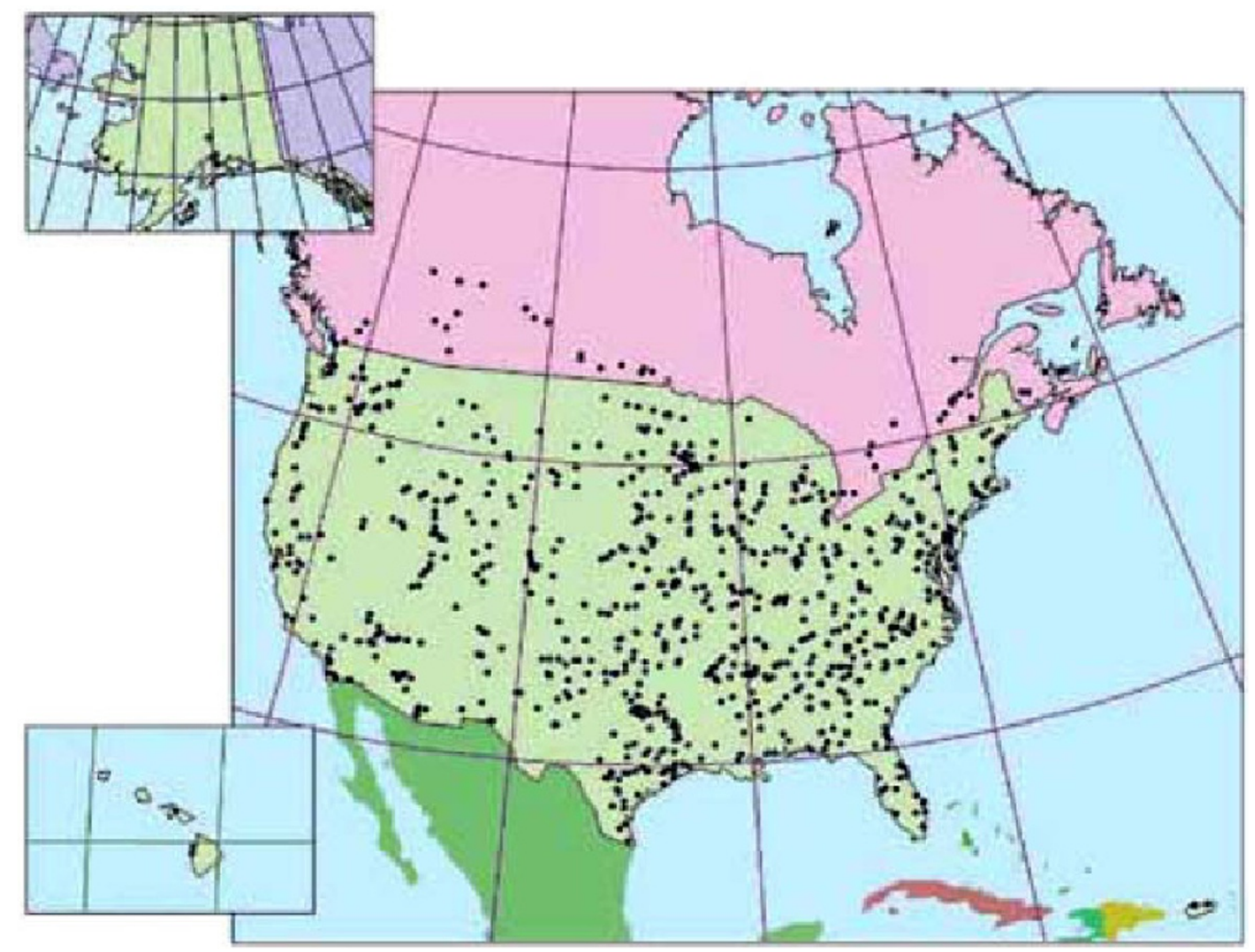

Fig. 1 Distribution of LTPP pavement test sections 


\section{MEPDG: an overview}

\subsection{MEPDG design approach}

The design approach provided in MEPDG consists of three major stages, shown in Fig. 2 [1]. Stage 1 of this procedure is to develop input values. In this stage, potential strategies are identified and foundation analysis is conducted. In addition, pavement materials inputs, traffic characterization data, and hourly climatic data (temperature, precipitation, solar radiation, cloud cover, and wind speed) from weather stations are developed. Stage 2 consists of the structural/performance analysis. The analysis approach begins with the selection of an initial trial design. The trial section is analyzed incrementally over time using the pavement response and distress models, and the outputs of the analysis are accumulated damage amount of distress and smoothness over time. A pavement structural design is therefore obtained through an iterative process in which predicted performance is compared against the design criteria for the multiple predicted distresses until all design criteria are satisfied to the specified reliability level. Stage 3 of the process includes the evaluation of the structurally viable alternatives, such as an engineering analysis and life cycle cost analysis.

\subsection{Hierarchical design inputs}

The hierarchical approach to design inputs is a feature of MEPDG not found in existing design procedure [1], which provides the designer with flexibility in obtaining the design inputs for a design project based on the criticality of the project and the available resources. The hierarchical approach is employed with regard to traffic, materials, and environmental inputs.

Level 1 inputs provide for the highest level of accuracy and would have the lowest level of uncertainty or error. Level 1 inputs would typically be used for designing heavily trafficked pavements or wherever there are dire safety or economic consequences of early failure. Level 1 material input require laboratory or field testing, such as the dynamic modulus testing of hot-mix asphalt concrete, site-specific axle load spectra data collections, or nondestructive deflection testing.

Level 2 inputs provide an intermediate level of accuracy. Level 2 inputs typically would be userselected, possibly from an agency database, could be derived from a limited testing program, or could be estimated through correlations.

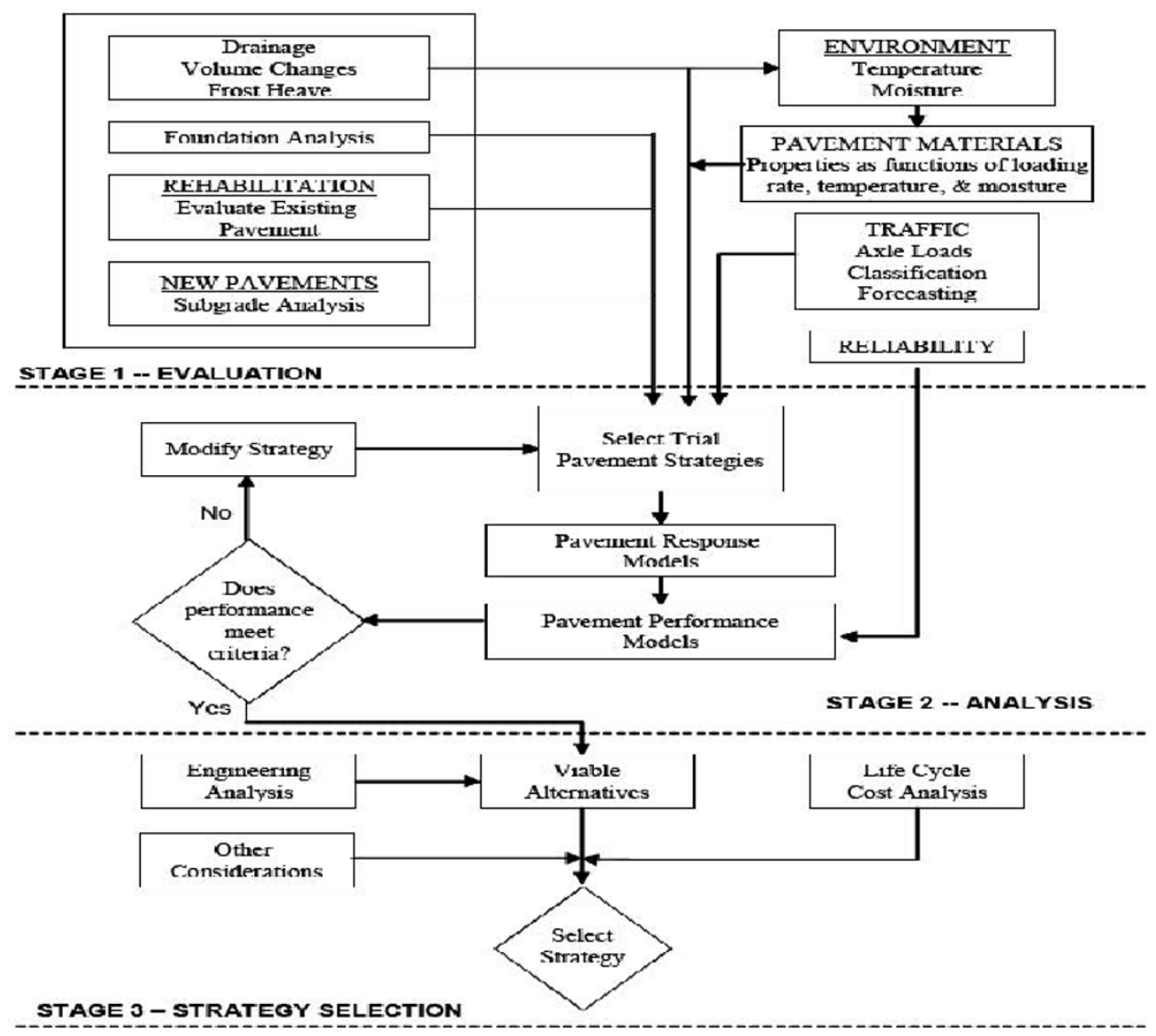

Fig. 2 The three-stage scheme of the MEPDG process [1] 
Level 3 inputs provide the lowest level of accuracy. This level might be used for design where there are minimal consequences of early failure, such as lower volume roads. Inputs typically would be user-selected values or typical averages for the region. National default values are provided in the MEPDG software and could be used as level 3 inputs.

\subsection{Environmental effects}

The MEPDG approach fully considers the changes of temperature and moisture profiles in the pavement structure and subgrade over the design life of a pavement through the incorporation of the Enhanced Integrated Climate Model (EICM) into the MEPDG design software. The EICM is a one-dimensional coupled heat and moisture flow program that simulates changes in the behavior and characteristics of pavement and subgrade materials in conjunction with climatic conditions [1].

In addition, the MEPDG software provides an available database from more than 800 weather stations from the National Climatic Data Center (NCDC) throughout the United States, which allows the user to select a given station or to generate virtual weather stations for a project site under design.

\subsection{Traffic characterization}

Instead of using Equivalent Single Axle Load (ESAL) as in the 1993 AASHTO Guide [2] to characterize traffic throughout the pavement design life, MEPDG requires the full axle-load spectrum traffic inputs for estimating the magnitude, configuration and frequency of traffic loading to accurately determine the axle loads that will be applied on the pavement in each time increment of the damage accumulation process. The typical traffic data required for the MEPDG are categorized as follows [1]:

- Truck traffic volume: in the base year and the estimated growth rate in the design life;

- Truck traffic volume adjustment factors: hourly and monthly;

- Axle load distribution factors: load spectra and vehicle class distribution;

- General traffic inputs, such as axle configuration, wheelbase, and axles per truck.

\subsection{Material characterization}

The material parameters needed for the design process are classified into three major groups: (1) pavement response model material inputs, (2) material-related pavement distress criteria, and (3) other material prop- erties [1]. The pavement response model material inputs relate to the moduli and Poisson's ratio used to characterize layer behavior within the specific model. Material parameters associated with pavement distress criteria normally are linked to some measure of material strength (shear strength, compressive strength, modulus of rupture) or to some manifestation of the actual distress effect (repeated load permanent deformation, fatigue failure of PCC materials). The "other" category of materials properties constitutes those associated with special properties required for the design solution. Examples of this category are the thermal expansion and contraction coefficients of both PCC and asphalt mixtures.

\subsection{Subgrade/foundation design inputs}

Different means for subgrade or foundation characterization alternatives exist, including [1]:

- Laboratory testing of undisturbed or reconstituted field samples recovered from the subsurface exploration process;

- Nondestructive testing of existing pavements with similar subgrade materials;

- Intrusive testing such as the Dynamic Cone Penetrometer (DCP);

- Reliance on an agency's experience with the subgrade type.

Laboratory testing and Nondestructive Deflection Testing (NDT) are recommended as the primary characterization methods. An agency's experience can and should supplement these two methods.

\subsection{Pavement performance}

Pavement performance is primarily concerned with functional and structural performance. The structural performance of a pavement relates to its physical condition (such as fatigue cracking and rutting for flexible pavements, and joint faulting, and slab cracking for rigid jointed pavements). Several of these key distress types can be predicted directly using mechanistic concepts and are considered in the design process.

Ride quality is the dominant characteristic of functional performance, as measured by the International Roughness Index (IRI). In MEPDG, IRI is estimated incrementally over the entire design period by incorporating distresses such as cracking, rutting, faulting, and punchouts as the major factors influencing the loss of smoothness of a pavement. The general hypothesis of the smoothness models is that the various distresses resulting in significant changes in smoothness are repre- 
sented by separate components within the MEPDG models, as shown in Eq. (1) [1].

$$
S(t)=S_{0}+\left(a_{1} S_{D(t) 1}+\cdots+a_{n} S_{D(t) n}\right)+b_{j} S_{j}+c_{j} M_{j},
$$

where $S(t)$ denotes pavement smoothness at a specific time, $t$ (IRI, in/mi); $S_{0}$ initial smoothness immediately after construction (IRI, in/mi); $S_{D(t)}(i=1$ to $n$ ) change of smoothness due to the $i$ th distress at a given time $t$ in the analysis period; $a(i=1, \cdots, n), b_{j}$ and $c_{j}$ are regression constants; $S_{j}$ change in smoothness due to site factors (subgrade and age); $M_{j}$ change in smoothness due to maintenance activities.

\subsection{Structural modeling}

Proper structural modeling is the heart of a mechanistic-based design procedure. The structural models used for flexible pavements include the multilayer elastic program JULEA for linear elastic analysis [1], and the 2-D finite element program DSC2D [8] for finite element analysis (FEA), if the user opts to use the Level 1 hierarchical inputs to characterize the non-linear moduli response of any unbound layer materials.

The structural model for rigid pavement analysis is a 2-D finite element program, ISLAB2000 [9]. This FEAbased structural model was used as a basis for developing rapid solution neural networks (NN). These $\mathrm{NN}$ provide accurate and virtually instantaneous solutions for critical responses and were developed so that the large numbers of computations needed could be accomplished rapidly.

This MEPDG procedure is the first to include the capability to accumulate damage on a monthly basis over the entire design period. This approach attempts to simulate how pavement damage occurs in nature, incrementally load by load over continuous time periods. This approach allows the use of elastic moduli within a given time period that are representative of that time increment. This procedure also allows for the aging of paving materials.

\subsection{Design reliability}

Within the context of the MEPDG, reliability of a given design is the probability that the performance of the pavement predicted for that design will be satisfactory over the time period under consideration. Design reliability, $R$, is defined as the probability $P$, that each of the key distress types and smoothness will be less than a selected critical level over the design period [1].

$$
\begin{aligned}
& R=P(\text { performance over design period }< \\
& \text { critical level }) .
\end{aligned}
$$

Several design features other than thickness (which is defined in the current 1993 AASHTO Guide) could be considered to improve the reliability estimate of the design. The prediction is based on mean or average values for all inputs, as illustrated in Fig. 3 [1].

Assuming that distress and IRI are approximately normally distributed, the standard deviation for each distress type was determined from the model prediction error (standard error of the estimate) from calibration results used for each key distress. Given the mean and standard deviation of a normal distribution, the estimate cracking at the desired reliability level can be calculated as follows (cracking as an example) [1]:

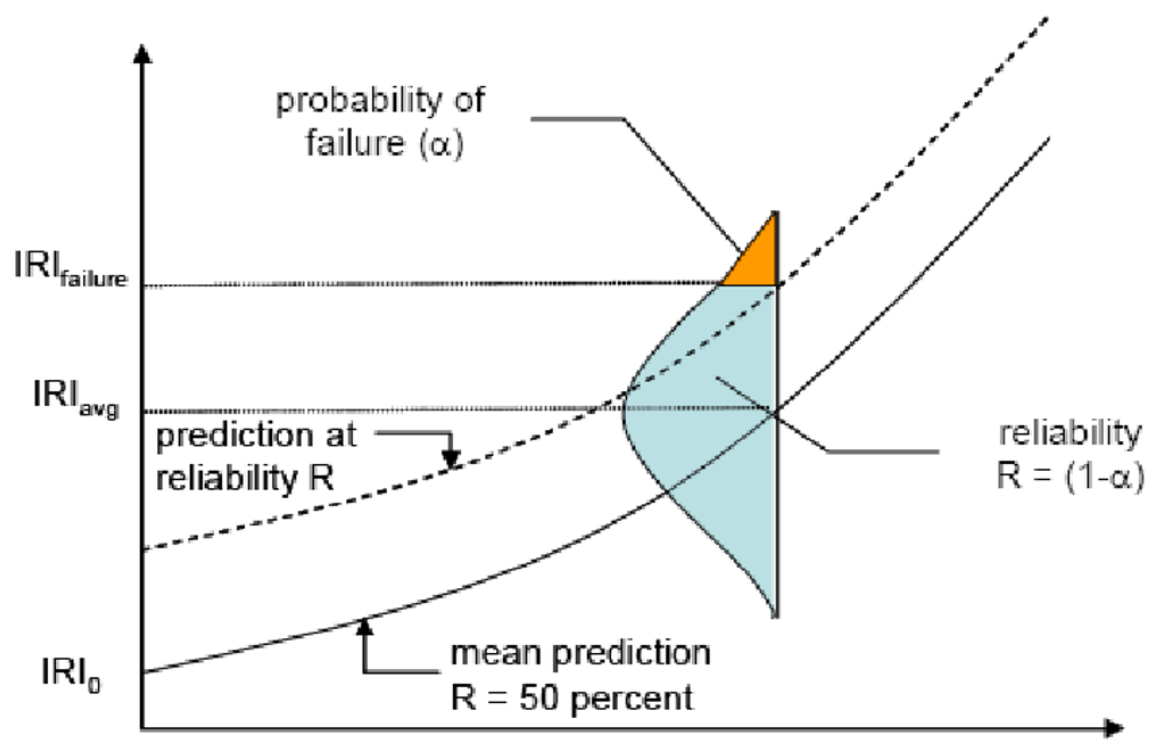

Fig. 3 Design reliability concept for smoothness (IRI) in MEPDG [1] 
CRACK_P $=$ CRACK_mean + STDmeas $\times Z_{p}$,

where CRACK_P denotes cracking at the reliability level $p$; CRACK_mean is the predicted cracking using the deterministic model with mean inputs (corresponding to 50 percent reliabality); STDmeas is the standard deviation of cracking from national calibration; and $Z_{p}$ denotes the standardized normal deviate corresponding to reliability level $p$.

\section{State-of-the-art research and implement- ation practices of MEPDG}

In order to implement the MEPDG procedure for state highway agencies, the NCHRP 1-37A report identifies several challenges and issues as follows which need to be tackled in advance [1]:

- Data for design inputs, how the agency will collect the inputs, and establishing a database for inputs;

- Performance and reliability design criteria;

- Existing and new testing equipment required;

- Computer hardware and software requirements;

- Local calibration and validation of distress models;

- Establishing a database of projects;

- Training requirements for staff doing pavement design;

During the past 10 years, several NCHRP projects supporting the implementation and adoption of MEPDG have been conducted in the United States as summarized in Table 1.
Several states have undertaken research activities designed to facilitate implementation of the MEPDG. Interestingly, most states are pursuing similar activities in these efforts: (1) estimation of the sensitivity of pavement responses to changes in design inputs; (2) evaluation of materials and traffic inputs; (3) establishment of allowable/acceptable pavement performance criteria; and (4) calibration of the MEPDG to local materials, climate, and traffic conditions. Use the state of Arkansas as an example, the studies been and being conducted are shown in Table 2.

In the following sessions, each category of the studies is explored.

\subsection{Sensitivity analysis}

MEPDG requires over 100 inputs to model traffic, environmental, materials, and pavement performance to provide estimates of pavement distress over the design life of the pavement. Many designers may lack specific knowledge of the data required. Sensitivity study is beneficial to assess the relative sensitivity of the models used in MEPDG to inputs relating. This sensitivity analysis may aid designers in focusing on those inputs having the most effect on desired pavement performance. This task is performed by running the same problem several times while changing the value of a variable and evaluating the results to determine if that variable has a significant, moderate, or minor effect on predicted pavement performance.

Table 1 NCHRP projects supporting implementation and adoption of MEPDG

\begin{tabular}{llc}
\hline Project number & \multicolumn{1}{c}{ Project title } & Status \\
\hline NCHRP 01-37 & Development of the 2002 guide for the design of new and rehabilitated pavement structures & Completed \\
NCHRP 01-39 & Traffic data collection, analysis, and forecasting for mechanistic pavement design & Completed \\
NCHRP 01-40A & Independent review of the recommended mechanistic-empirical design guide and software & Completed \\
NCHRP 01-40B & User manual and local calibration guide for the M-E pavement design guide and software & Completed \\
NCHRP 01-40D & $\begin{array}{l}\text { Technical assistance to NCHRP project 1-40A: versions 0.9 and 1.0 of the M-E pavement design } \\
\text { software }\end{array}$ & Completed \\
NCHRP 01-41 & Models for predicting reflection cracking of hot-mix asphalt overlays & Completed \\
NCHRP 01-42A & Models for predicting top-down cracking of hot-mix asphalt layers & Completed \\
NCHRP 01-47 & Sensitivity evaluation of MEPDG performance prediction & Active \\
NCHRP 01-48 & Incorporating pavement preservation into the MEPDG & Active \\
NCHRP 01-50 & Quantifying the Influence of geosynthetics on pavement performance & Pending \\
NCHRP 09-30 & $\begin{array}{l}\text { Experimental plan for calibration and validation of HMA performance models } \\
\text { for mix and structural design }\end{array}$ & Completed \\
\hline
\end{tabular}


Table 2 Research projects related to the MEPDG sponsored by AHTD

\begin{tabular}{clr}
\hline Project number & \multicolumn{1}{c}{ Project Title } & Status \\
\hline MBTC-2027 & Investigation of the effect of fines on base course performance & Completed \\
MBTC-2032 & Development of testing protocol and correlations for resilient modulus of subgrade soils & Completed \\
TRC-0302 & AASHTO 2002 pavement design guide design input evaluation study & Completed \\
TRC-0304 & Dynamic modulus and static creep behavior of hot-mix asphalt concrete & Completed \\
TRC-0402 & Projected traffic loading for mechanistic-empirical pavement design guide & Completed \\
TRC-0602 & Development of a master plan for calibration and implementation of the M-E pavement design guide & Active \\
TRC-0702 & Database support for the new mechanistic-empirical pavement design guide & Completed \\
TRC-0708 & PCC materials input values for mechanistic-empirical pavement design guide & Completed \\
TRC-0902 & Validation of the enhanced integrated climate model for pavement design in arkansas & Active \\
TRC-1003 & Local calibration of the MEPDG & Active \\
TRC-1203 & Data Preparation for Implementing DARWin-ME & Pending \\
\hline
\end{tabular}

There are two types of sensitivity analyses: (1) sensitivity of predicted performance to design inputs; and (2) sensitivity of predicted performance to calibration coefficients. The first sensitivity analysis is used to recommend the input level (e.g., Level 1, 2 or 3) for each design input for future calibration and implementation. The second sensitivity analysis is used to identify the most significant coefficients among all calibration coefficients so that the data requirements and amount of efforts for local calibration can be reduced.

Various agencies or institutes have conducted similar rese arch, such as the University of Arkansas [10], Iowa State Uni versity [11], University of Kentucky [12], the University of California, Davis [13], New Jersey Department of Transportat ion [14], and Texas Transportation Institute [15].

Based on the sensitivity analyses, it is suggested that the following input parameters be determined or analyzed further at state level if the MEPDG is implemented in the future: (1) climate data; (2) traffic loading spectra data; (3) HMA inputs: dynamic modulus, indirect tensile strength and creep compliance; (4) PCC inputs: coefficient of thermal expansion, modulus of rupture, compressive strength, and Poisson's ratio; (5) base input: resilient modulus; and (6) subgrade input: resilient modulus.

\subsection{Material characterization}

\subsubsection{Dynamic modulus $E^{*}$ for asphalt mixture}

The dynamic modulus of HMA is the most significant input used in the structural design of asphalt pavements. The main objectives of $E^{*}$ characterization include (1) to develop a dynamic modulus database and determine the data variability for $\left|E^{*}\right|$ input Level 1 in MEPDG; (2) to evaluate a predictive equation for $\left|E^{*}\right|$ input Levels 2 and 3 in MEPDG; and (3) to identify the appropriate $\left|E^{*}\right|$ input level for initial implementation of MEPDG [16-18].

In Arkansas, the testing program for the dynamic modulus included 21 HMA mixtures based on four aggregate sources, three aggregate sizes, and two binder grades [19]. The dynamic modulus test was performed in the laboratory in accordance with AASHTO TP-62, Standard Test Method for Determining Dynamic Modulus of Hot-Mix Asphalt Concrete Mixtures, at five temperatures, including - 10, 4.4, 21.1, 37.8, and 54.4 ${ }^{\circ} \mathrm{C}\left(14,40,70,100\right.$, and $\left.130^{\circ} \mathrm{F}\right)$, and six frequencies, including $25,10,5,1,0.5,0.1 \mathrm{~Hz}$. Three replicates for each HMA mixture were prepared at optimum binder content. After the mixtures were compacted to 150 $\mathrm{mm}$ diameter and $170 \mathrm{~mm}$ height at two air void levels, the test specimens, $100 \mathrm{~mm}$ diameter and $150 \mathrm{~mm}$ height, were cored and cut from the compacted samples. It was found that the predicted dynamic modulus values in MEPDG agreed quite well with the laboratory measured ones.

\subsubsection{Coefficient of thermal expansion (CTE) for Port- land cement concrete}

Among these parameters such as gradation, elastic modulus and compressive strength, coefficient of thermal expansion (CTE) was found to be very significant for rigid pavement distresses. However, CTE has not been included as a variable in material specifications or in most laboratories. 
Project TRC-0708 sponsored by the Arkansas Highway and Transportation Department (AHTD) was supported to address this problem [20]. Twelve common PCC pavement mixtures in Arkansas using four types of aggregates (limestone, syenite, sandstone and gravel) and three different cement proportions were tested. Analysis of variance and sensitivity analyses were performed to evaluate the influence of mixture properties on the CTE and the effect on pavement performance predictions of using Level 1- and 3-CTE inputs. It was found that the type of coarse aggregate in the PCC mixture significantly influenced the CTE. But cement content and concrete age were not significant. In addition to findings about CTE, this study documented the procedure of laboratory testing on PCC materials for MEPDG. The results set up a reference for rigid pavement design in Arkansas. In this study, the rupture modulus, compressive modulus, and Poison ratio were also tested for the mixtures. Similar study has been conducted by several other agencies [21-23].

\subsubsection{Resilient modulus}

Realizing the important role of resilient modulus in MEPDG, AHTD supported two research projects addressing the resilient modulus of subgrade soils [24- 25] and unbound base [26]. Ten sites were selected such that a wide variety of subgrade soils typically encountered in Arkansas are represented. Resilient modulus was measured using different methods including laboratory triaxial test, falling weight deflectometer (FWD), standard penetration test and spectral analysis of surface waves (SASW). In another study on unbound base, five quarries were selected to represent the main geologic materials (limestone, dolomite, sandstone, syenite, novaculite) for crushed stone aggregate produced in Arkansas. Index testing, triaxial tests, shear strength, hydraulic conductivity were measured. These two studies established a reliable reference for Arkansas to implement MEPDG.

\subsection{Climatic impacts}

The enhanced integrated climatic model (EICM) is fully incorporated in the MEPDG software that allows users to select adjacent weather stations to generate a virtual weather station (VWS), and therefore very limited research efforts have been devoted to verify the effectiveness of the VWS data generated using the MEPDG software. Zaghloul et al [27] found that using different weather stations to generate VWSs in MEPDG would result in significant differences in pavement performances, even though the two pavement sections under study were designed with the same structures and to be built about 15 miles $(24 \mathrm{~km})$ apart. The observation is against conventional engineering wisdom. In the NCHRP 1-37A report [1], it is suggested that "the EICM has been validated only on a limited basis, and further comparison of outputs with actual field conditions has been recommended".

$\mathrm{Li}$ and Wang [28] conducted a comparison analysis to evaluate the accuracy of the MEPDG generated VWS data by comparing the climatic data from corresponding automated weather stations (AWS) in the Long-Term Pavement Performance (LTPP) database. It is observed that most VWS climatic data estimate the actual weather data reasonably well. However, in some cases significant differences are observed. It is recommended in this research:

- Using as many applicable nearby weather stations as possible for estimating the climatic parameters provides more accurate results than using the closest weather station.

- Elevation differences (between the project site and the nearby weather stations) significantly affect the accuracy of the MEPDG generated virtual climatic data.

- The distance between the project site and the contributing weather stations does not significantly influence the MEPDG generated virtual climatic parameters.

- Variations of climate data are observed to have significant influence on asphalt concrete (AC) rutting, while much less influence is observed for the total rutting. IRI is the least influenced parameter for both flexible and rigid pavement.

Johanneck and Khazanorich [29] details the effort required to compare performance predictions for composite pavement consisting of asphalt cement over Portland cement concrete (PCC) for 610 locations across the United States. Although in general the results agree with the anticipated trends of environmental effects on pavement performance, the prediction of performance according to the predicted transverse cracking in the PCC layer was found to contain inconsistencies. These inconsistencies are attributed to the quality of the climatic data. The paper concludes that the MEPDG climatic database should be cleansed of incomplete or questionable climatic data files to ensure reliable performance prediction.

Breakah et al. [30] presents a case study to show the importance of using accurate climatic data by developing climatic files for each county in the state of Iowa and studying the difference between the files available within MEPDG that are based upon 9 years of historical regionally averaged data and the created files that consist of site-specific data for 34 years of the historical record. This case study has illustrated the critical role that accurate climatic data have in the MEPDG and thus it is 
very likely that forecasting climatic data for use in developing pavement designs for future designs will be very important to developing appropriate designs. It is recommended to use more comprehensive climatic data and need to be continuously updated for use in the mechanistic-empirical pavement design guide. It is also recommended to develop forecast files that cover the project duration and run these used files to simulate the project performance during the expected project life.

\subsection{Traffic load spectra characterization}

This axle load spectra approach is widely viewed as a quantum leap forward in pavement design technology [10-11]. However, there is no doubt that the load spectra approach is much more complex than the existing ESAL based approach and several challenges exist [31]. First, for a long time there has been a gap between traffic and pavement engineers in understanding the needs for traffic data in pavement design. Pavement and traffic engineers need to share their knowledge and experience together when using MEPDG. Secondly, the proposed Truck Traffic Classification (TTC) system to describe the distribution of trucks traveling on the roadway is new to both traffic and pavement engineers. The third challenge is that the traffic data collected from the automated traffic collection sites often have errors, especially the data collected from the WIM sites [32-33]. It consumes large amount of resources, such as labor, time, and money to process the data by using currently available methods to process the data check [34]. Fourth, the sizes of the raw traffic data files are huge. For example, the size of truck weight data collected in Arkansas can be $200 \mathrm{MB}$ to $300 \mathrm{MB}$ in text file format per month. With several years of monitoring data, the processing of the raw data becomes tedious and time consuming. It is impractical to manually process those data files even with computer assistance. In addition, there will be $10 \mathrm{~s}$ of thousands of traffic data sets needed to be prepared to characterize traffic loading for a particular design in MEPDG. This process needs to be automated with software.

Several existing software programs have the functionalities to process data and generate reports. For example, Trafload, a computer program developed under NCHRP Project 1-39 [35] for generating traffic inputs for MEPDG, still cannot fulfill many of the requirements for MEPDG $[32,36]$. Several research projects develop Excel ${ }^{\circledR}$ spreadsheets to reduce raw vehicle classification data and weight data, and to generate volume adjustment factors and axle load spectra for MEPDG [32, 36]. However, the updating procedure needs to be repeated manually if new traffic monitoring data are available. In addition, the traffic data check process is based on subjective judgment of the histograms of the raw data. A windows-based database interface, PrepME [37], was developed at the University of Arkansas with the functionalities customized to the implementation of MEPDG. Particularly the interface for Weigh-In-Motion (WIM) based traffic loading spectrum analysis has attracted extensive attention from AASHTO, FHWA, and various state DOTs. It can automatically pre-process based on clearly defined rules, efficiently import the raw traffic data, and generate the required traffic inputs for the MEPDG software. The traffic data check interface is shown in Fig. 4. This research has been implemented as a pooled-fund study [38].

Level 1 traffic WIM data are available. In such case, Levels 2 or 3 (regional and state-wide average) traffic inputs can be considered for design by combining existing site-specific data from WIM systems located on sites that exhibit similar traffic characteristics. The sites with similar traffic patterns can be classified as a truck loading group. How to qualify these similarities and how to develop loading groups for pavement design is a challenge and becoming a recent interest in the US as more state agencies started various efforts to implement MEPDG with WIM data.

Ideally, Level 1 traffic inputs for MEPDG can be obtained from a WIM system operating continuously at the design site over extended periods of time. In practice, however, when new pavements are designed, no prior Level 1 traffic WIM data are available. In such case, Levels 2 or 3 (regional and state-wide average) traffic inputs can be considered for design by combining existing site-specific data from WIM systems located on sites that exhibit similar traffic characteristics. The Traffic Monitoring Guide (TMG) [39] recommends a combination of statistical cluster analysis (objectively) and analyst knowledge or expertise (subjectively) to create factor groups of sites with similar truck traffic patterns. Truck weight road groups are then developed based on a combination of known geographic, industrial, agricultural, and commercial patterns, along with knowledge of the trucking patterns that occur on specific roads. Papagiannakis et al. [40] are among the first to adopt clustering techniques to establish similarities in vehicle classification and axle load distributions between traffic data collection sites using the long-term pavement performance database, so as to estimate traffic input for MEPDG with limited site-specific traffic data. Various State Department of Transportation (DOTs) deployed clustering algorithms to develop traffic inputs in different regions to support the mechanistic-empirical based pavement design [41-44].

Wang and $\mathrm{Li}$ [31] analyzed the WIM data collected in the state of Arkansas using cluster analysis methodologies to identify groups of WIM sites with similar traffic characteristics. Combining with the loading clusters, LongTerm Transportation Planning factors currently adopted in Arkansas are adopted as the influencing criteria to develop the truck loading groups. The most significant in- 
fluencing criteria are identified using the Fisher's exact test. Consequently, truck loading groups and their categorical logit models are developed for potential pavement design when no actual WIM station exists at the design site. The developed method for determining truck loading groups will simplify the understanding and applicability of the traffic patterns and ultimately ease the preparation of the traffic load spectra inputs based on WIM data for the MEPDG procedure.

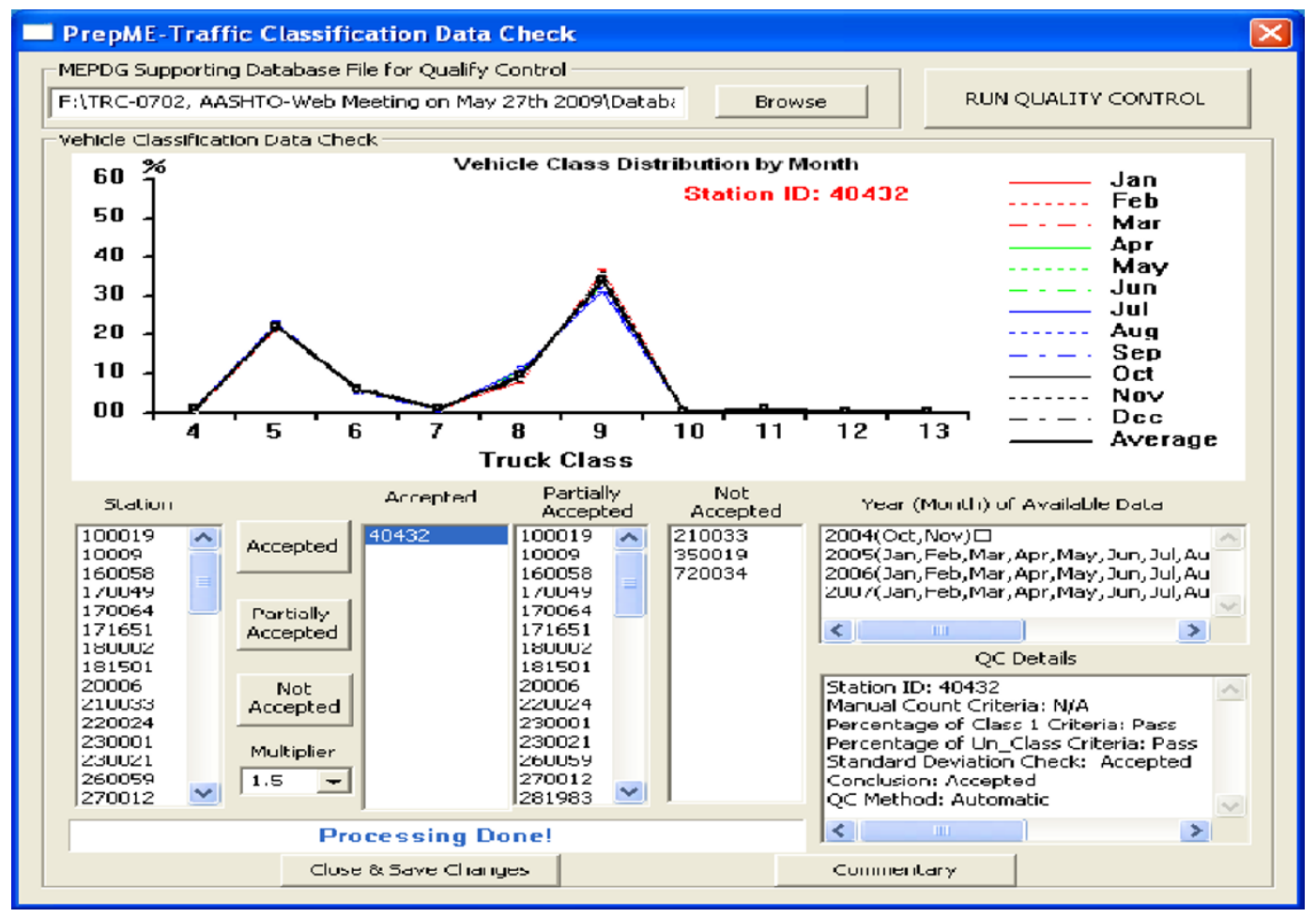

(a) Vehicle classification data

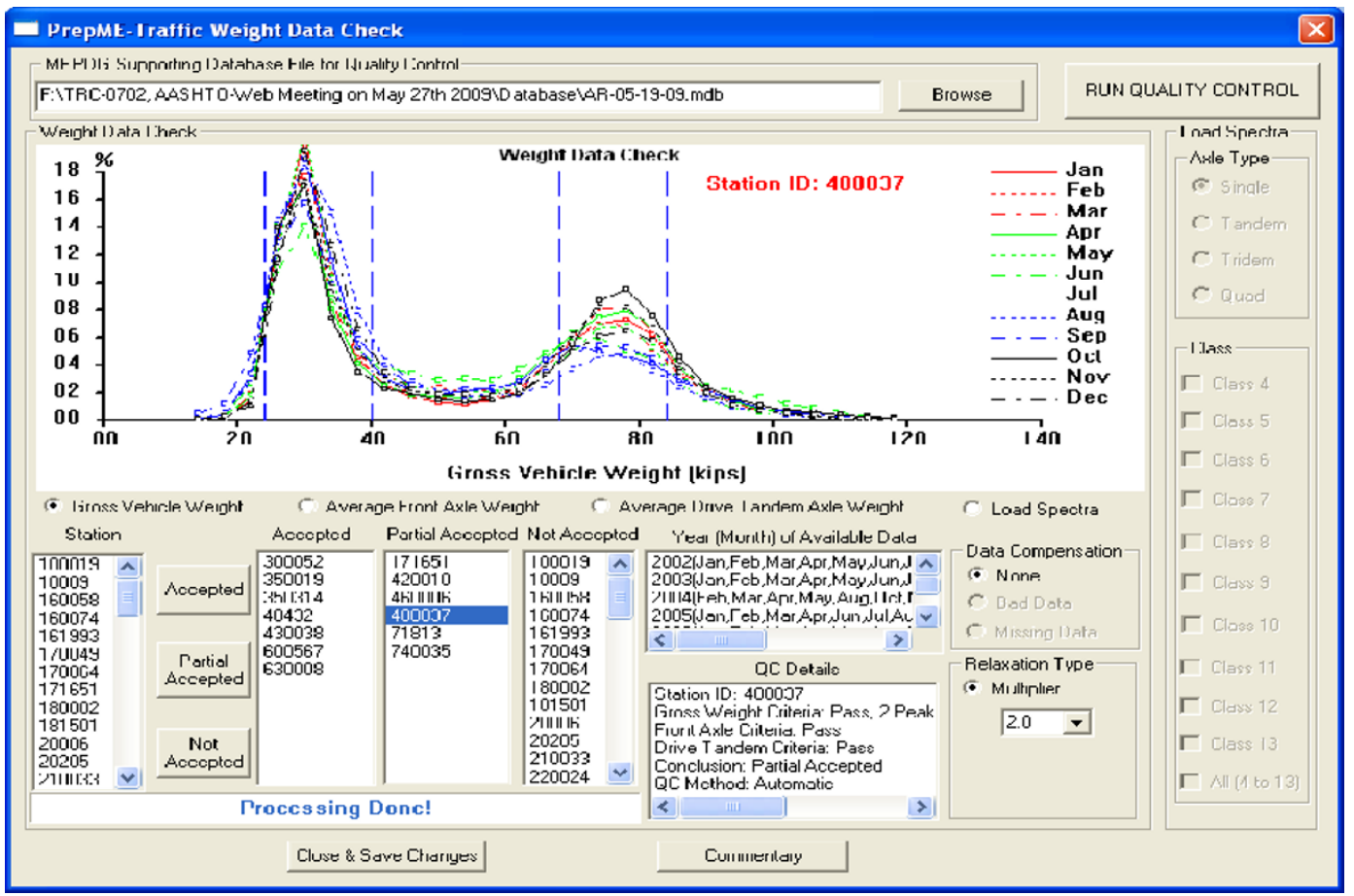

(b) Weight data

Fig. 4 Traffic data quality check in PrepME [37] 


\subsection{Design studies and design handbook}

Most highway agencies use AASHTO methods for the design of pavement structure and are lack of the design experience with MEPDG. Comparative studies are necessary to be conducted between the MEPDG and the current AHTD pavement design procedures based on the 1993 AASHTO Guide. The experimental plan for this study includes:

- Comparison of the designs for typical low, medium, and high volume roadways;

- Comparison of the designs for different reliability levels; and

- Comparison of the designs using the MEPDG based on low, medium, and high design performance criteria to those using the AASHTO design procedures.

The results of these studies are used to determine if the MEPDG under-designs, over-designs, or adequately designs pavements. In addition, the NCHRP 1-37A reports [1], which are the technical support for MEPDG, has a length of more than 2000 pages, and therefore, it is not the practical handy resources for daily pavement design. The development of a much more concise MEPDG based design handbook will be a great benefit to the designers.

\subsection{Local calibration}

The currently available MEPDG was calibrated using national wide data from the Long-Term Pavement Performance (LTPP) program. Because of the difference between national condition and local condition such as climate, material properties, traffic patterns, construction and management techniques, MEPDG needs to be validated and calibrated for local conditions.

The goal of local calibration is to eliminate bias between national models and local conditions, o reduce the standard error associated with the prediction equations, and to considers the difference of materials, construction specifications, policies on pavement preservation and maintenance across the nation. Therefore, local calibration is usually conducted after the completion of traffic and material characterization, and serves as a cumulative effort of all implementation projects for a state highway agency. Upon the completion of local calibration, MEPDG would be used for routine design by local agencies.

The procedure of local calibration includes experimental design, data collection, MEPDG modeling, eliminate bias, reduce standard error, and validation. A national guideline developed by NCHRP Project 1-40 B is also available for local agencies to conduct the cali- bration task [45]. Calibration projects are completed or undergoing in many states such as Wisconsin [46], Montana [47], Florida [48], North Carolina [49], Texas [50], Minnesota [51], Washington [52], Ohio [53], and Arkansas [54]. Improvement of MEPDG predictions were reported by most of these researches. Some challenges and issues observed during local calibration will be discussed later in this paper.

\subsection{Low volume roads}

The three million miles of low volume roads (LVRs) under the control of over 35000 local government agencies in the United States constitute 70 percent of roadway mileage but carry only 15 percent of all traffic [55]. A survey conducted at the University of Arkansas [56] revealed that 37 of the 48 states, including the State of Arkansas, in the continental United States design their LVRs using the AASHTO design method. The LVR procedure used by AASHTO [2] is essentially the same as the corresponding procedure for high volume pavements. For low-volume roads, design charts for flexible pavements are similar to those for highway pavement design, but the input requirements have been simplified and methods are provided to estimate some input values required for design to allow local agencies the option of using "standard" inputs for design. As a result, local low-volume roads were typically constructed using a standard section, such as a double surface treatment over a specified thickness of granular base material. However, as the LVRs began to deteriorate, it was apparent that these 'standard' sections were often inadequately designed [56].

Even though significant research towards the implementation of the MEPDG has been conducted, all the efforts are being focused on high-volume roads, not low volume roads. Li and Xiao [57] developed a comprehensive low-volume Roads design catalog suitable for the State of Arkansas. This study documents the result of an exhaustive literature review of the Arkansas's research projects on the implementation of MEPDG and applies the results to the LVRs design in Arkansas. The catalog offers a simplified and practical approach to low-volume design by providing a variety of acceptable design alternatives for a comprehensive combination of site conditions (traffic, location, subgrade, and aggregate type).

\subsection{FHWA design guide implementation team (DGIT)}

Because FHWA considers implementation of MEP DG a critical element with highest priority in improvin $\mathrm{g}$ the National Highway System, a Design Guide Imple mentation Team (DGIT) (http://www.fhwa.dot.gov/pav 
emen/dgit/) has been organized to immediately begin the process of informing, educating, and assisting FHWA's fi eld offices, State highway agencies, industry and other $\mathrm{s}$ about MEPDG. Since it was launched, it has offered numerous workshops, technical support all around the nation.

\subsection{LTPP efforts}

The LTPP database was critical to the development of the MEPDG, as it is the only source of comprehensive pavement data representing a wide range of loading, climate, and subgrade conditions with varying structural compositions across the country.

The LTPP database is also serving as a critical tool in implementing MEPDG. Local validation and calibration will rely heavily on the LTPP database as many agencies do not otherwise have the data necessary to complete this endeavor LTPP sites provide typical values for many of the MEPDG inputs, and will play in evaluating, calibrating, and validating the MEPDG on a local level.

Recently, LTPP has devoted extensive efforts to explore the traffic data for MEPDG traffic inputs, which are accessible in the LTPP Traffic Analysis Software (LTAS) data tables [58] containing monitored traffic data aggregated at the daily, monthly and annual levels customized for MEPDG implementation usage.

It is not practical to perform MEPDG Level 1 laboratory $\left|E^{*}\right|$ tests on material samples from LTPP test sections due to a lack of materials, budget limitations, and the absence of an accepted test method for field samples obtained from relatively thin pavement structures. However, the LTPP database contains data that could be used to estimate the $\left|E^{*}\right|$ master curve and associated shift factors. A recent research project [59], LTPP Computed Parameter: Dynamic Modulus (FHWA-HRT-10-035), has achieved these goals. The primary objective was to develop estimates of the dynamic modulus of HMA layers on LTPP test sections following the models used in the MEPDG. As part of this project, existing models used to estimate $\left|E^{*}\right|$ values were evaluated, and additional models were developed based on the use of artificial neural networks (ANNs). The models utilize readily available mixture and binder information to estimate dynamic modulus. In the most recent LTPP standard data release 25.0 released in January 2011, the research results were incorporated and seven new tables were added to the testing module (TST) of the LTPP database. These tables include the inputs used in the predictions, $\left|E^{*}\right|$ estimates at five temperatures and six frequencies, sigmoidal functions (size and shape of the master curve), and shift factors. These data will provide a means of linking MEPDG inputs (for HMA analysis) to known field performance as measured on LTPP test sections.

\section{Challenges and future research}

\subsection{Sensitivity analysis}

Although studies have been conducted to relate predicted performance to differences in input parameter values, these studies have not addressed this relationship in a systematic manner to identify the relative influence of input parameter values on predicted performance. Moreover, these studies have not considered the combined effects of variations in two or more input parameter values on predicted performance in a comprehensive manner [60].

Research is needed to determine the degree of sensitivity of the performance predicted by the MEPDG to input parameter values. This information will help identify, for specific climatic region and traffic conditions, the input parameters that appear to substantially influence predicted performance. In this manner, users can focus efforts on those input parameters that will greatly influence the pavement design.

Currently the NCHRP $01-47$ project [60] is in progress to determine the sensitivity of the performance predicted by the MEPDG to variability of input parameter values. A summary of the input parameters and the degree of sensitivity of predicted performance to variations in values of each parameter and combination of parameters will be prepared.

\subsection{Climate impacts}

\subsubsection{Enhancement of EICM models}

The EICM is envisioned for use in predicting the environmental effects on pavements in MEPDG. The pavement temperature determination element of the software was originally developed at the University of Illinois as the climatic-material-structural (CMS) model. It is a heat transfer model that computes pavement temperatures based on a Fourier heat-transfer equation for transient heat flow [61]. The dependability and precision of the CMS model is a function of the quality of input values, including boundary conditions, climatic data, and materials' properties for the specific pavement structure. After being incorporated in MEPDG Version 0.7, the EICM has undergone some modification until it reached the most current version. This was done under NCHRP Project 9-23 [62], of which the main aim of the project was to calibrate the model in order to adjust the prediction of the moisture content and was based on a suction model. 
However, it is also important to understand that almost all of the level 2 and level 3 correlations presented in the current revision of the MEPDG have been developed from very limited site correlation studies of soil properties. For example, much of the correlations used in the EICM for soil-water characteristic curve (SWCC) and $K_{\text {sat }}$ were obtained from approximately only 30 field sites from NCHRP 9-23. Clearly developing and utilizing enhanced models and correlations from the 31000 soils in the national soil properties database developed based on the NCHRP 9-23A [63] project is an enhancement possibility that deserves consideration.

In addition, the equilibrium moisture condition in the EICM is based on a suction model that depends on the water table depth and on a soil-water characteristic curve (SWCC) model that is functionally dependent on simple soil properties. As pointed in the NCHRP 9-23A report, the enhancement of the EICM moisture content predictive models is a must:

- Refinement of resilient modulus, moisture model to account for soil type distribution;

- Refinement of SWCC models to account for hysteresis due to wetting/drying cycles;

- Recalibration of resilient modulus/R value relationship with a better database.

\subsubsection{Climate change}

Current highways are designed based on typical historic climatic patterns, reflecting local climate and incorporating assumptions about a reasonable range of temperatures and precipitation levels. Given anticipated climate changes and the inherent uncertainty associated with such changes, a pavement could be subjected to very different climatic conditions over the design life and might be inadequate to withstand future climate forces that impose stresses beyond environmental factors currently considered in the design process.

While much effort has been devoted to understanding the contribution of road transportation to emissions of greenhouse gases and mitigating the emission through transportation mode shift, engineers, however, have given little thought to whether current design standards are sufficient to accommodate climate change [64]. Meyer [65] suggests that transportation infrastructure can be affected significantly by changing environmental conditions. TRB Special Report 290 [66] recommends that the development of appropriate design standards to accommodate climate change is one of the most important possible adaptation strategies. As noted in the Cambridge Systematics' Gulf Coast study [67], the likely temperature change up to 2050 will not create a significant challenge to pavement design, but that the average temperatures and range in temperatures by 2100 would clearly make today's pavement design approach ineffective.

Recognizing that no comprehensive study has been conducted to quantify the impacts of climate change on pavement performance and design, and that most majorities of research projects were conducted based on an average change of the climatic factors, without considering the uncertainty of the change, to explore the impacts of potential climate change and its uncertainty on pavement performance deterioration and therefore pavement design deserves future research. Three important questions need to be answered: (1) How does pavement performance deteriorate differently with climate change and its uncertainty? (2) What's the risk if climate change and its uncertainty are not considered in pavement design? and (3) How do pavement designers respond and incorporate this change into pavement design process?

\subsection{Traffic data quality check}

Several publications have reported that traffic data collected from automated traffic collection sites often have errors, particularly WIM sites using temperaturedependent piezoelectric sensors [68-69]. The State of Washington reported that only 11 of 52 WIM sites provided data suitable for the development of traffic inputs for the MEPDG [70]. Tram and Hall [6] found that only 23 sites out of 55 WIM stations provided suitable classification data and only 10 stations provided good weight data for the development of statewide axle load spectra for Arkansas. Therefore, it is important to collect highquality WIM data and conduct quality check of WIM traffic data as well

Over the past several years, LTPP has been working to enhance its software used to process traffic data from the LTPP test sites. The LTPP Traffic Analysis Software (LTAS) [33] uses a 12-step Quality Control (QC) checks to review the data before it is loaded into the LTPP pavement performance database. In Traffic Monitoring Guide [39], two basic steps are recommended to evaluate recorded vehicle weight data. The logic underlying of the the process is based on the expectation of finding consistent peaks in the Gross Vehicle Weight (GVW) distribution at each site. However, this technique was originally developed by the Minnesota DOT in early 1990 and was later adopted by the LTPP program [71]. Whether this technique is still valid 20 years later is unknown. Therefore, it is recommended that the procedure be evaluated, calibrated, and validated. 


\subsection{Local calibration and implementation}

\subsubsection{Data contingency and quality}

The first and most reported challenge for local calibration is the small sample sizes of pavement sections available for the calibration and validation due to constraints in time and budget. In a traditional calibration and validation approach using split-sample testing, a portion of the data (half or more) is used for calibrating a model while the remaining data is reserved to validate the model accuracy. If the sample size of the dataset for one distress type is small, a half of that dataset is even smaller, which produces inaccurate calibration coefficients and less reliable prediction accuracy.

Von Quintus et al. [45] proposed to employ the Monte Carlo simulation using jackknifing for the calibration and validation of the pavement performance models in the MEPDG. Jackknifing approach uses one database for both calibration and validation. In this approach, the goodness-of-fit statistics are determined based on predictions from data that are independent of the calibration data, which indicates the accuracy of future predictions. The purpose of the simulation is to extend the calibrated models beyond constraints imposed by limited performance data.

In most cases local calibration has to rely on available data from state highway agencies' pavement management system (PMS). However, some issues have been reported:

(1) Missing data in the database. Engineers may be encounter that one project does not have aggregate gradation data, another project may not have asphalt binder grade, and another project may miss subgrade soil type. Default values or engineering judgment have to be applied at some point to fully model an existing project in MEPDG. According to NCHRP Project 9-30 [72], which suggested that all sensitive input parameters identified in the sensitivity analyses should be available at Level 1 for all test sections, sections with missing data may have to be excluded for calibration or forensic studies and laboratory testing being conducted to recover missing data. For example, trenching is to measure rutting within each layer, and coring is to determine the direction and/or depth of crack propagation.

(2) Local performance evaluation may be inconsistent between MEPDG and state practices. MEPDG was developed and calibrated using LTPP database. All performance parameters such as alligator cracking, transverse cracking, rutting and IRI are based on LTPP's guidelines and specifications. However, state highway agencies may have used different taxonomy and specification on pavement performance. For example, alligator cracking in LTPP was obtained by directly measuring the area that had undergone distress, whereas North Carolina DOT used a rating of 0 to 10 based on the severity of cracking. Therefore, parameters in PMS have to be converted to the parameters and units used in MEPDG before the data can be used for local calibration [49]. Differences between state PMS and LTPP have also been observed in Arizona [73] and Nebraska [74].

It should also be noted that local calibration is an iterative process. Periodic recalibration (i.e. every five years) is suggested whenever new mechanistic models and transfer functions are adopted in the design software. Recalibration would have better quality when new calibration data are available. The design software has to keep pace with the improvement of materials and construction technologies. Therefore, a well designed database support is necessary to manage the data for local calibration and simplify the calibration process. The database should be seamlessly connected with local PMS.

\subsubsection{Semi-rigid base models}

Accurate characterization of the fatigue behavior of chemically stabilized mixtures (CSM) is a very complex technical issue. The situation is further complicated by the fact that fatigue cracking in the material layer is not directly observed in the pavement surface. Therefore, at present, the CSM fatigue cracking and subsequent reflective cracking model has not been field calibrated. In the MEPDG software, the compressive strength (modulus of rupture), elastic modulus, and density are required inputs to the MEPDG for any cementitious or pozzolonic stabilized material. However, any changes made to the default values are not saved by the MEPDG software. The values entered always divert back to the default values when the software is run. As a result, Minnesota Department of Transportation (MNDOT) [45] recommended that the input parameters for the CAM materials should not be changed for analyzing semirigid pavements. Instead, the regional calibration refinement factors were used to reflect different quality CAM materials for the semi-rigid pavement structures used in Montana.

In addition, because calibration-validation data is nonexistent; no special reliability solution is available [1]. The reliability data that is used is simply the standard deviation (variance) associated with normal HMA fatigue cracking. Very few of the test sections included in the MNDOT calibration refinement study [45] had any appreciable fatigue cracking to accurately calibrate this prediction model, as also reported in the LTPP database.

Another set of vital information in the CSM fatigue subsystem is to identify [1], whether or not, a crack relief layer is present, separating the HMA layer from the CSM layer. If no layer is present (crack relief), then the 
fatigue cracking predicted in the CSM layer is used directly in the HMA reflected crack subsystem. If a crack relief is present, then it is assumed that no CSM fatigue cracking will be reflected through the HMA layer. For either scenario, it should be recognized that the fatigue damage in the CSM layer would yield a reduced CSM moduli for the next analysis period. This reduced CSM moduli, will increase the $E_{i} / E_{i+1}$ modular ratio in the HMA layer and subsequently increase the tensile stresses and strains to cause a greater level of HMA fatigue cracking. Unfortunately these attributes haven't been fully understood.

In addition, unbound crack relief layers have been successfully used in many parts of the world. However, the key to success is 100 percent associated with the designer's ability to keep all moisture from being "pended" in the crack relief layer. If poor drainage occurs the crack relief layer quickly becomes saturated, effective soil stress go to zero due to saturation and shear failures will be widespread in the system. How to simulate and model this interaction is a challenge.

\subsection{Mechanistic models}

Mechanistic models are the backbone of MEPDG. Currently only linear models are calibrated for general applications. Users of MEPDG should be aware of the limitation of MEPDG in the perspective of mechanistic simplification and the research needs for better mechanistic models. For example, asphalt concrete is a viscoelastic material. Simplification is made mainly owe to the time-dependent property of a viscoelastic material is always very challenging and also that flexible pavement is a layered structure which further complicates the modeling work [75]. Researchers are building models to better consider the influence of viscosity, plasticity and other nonlinear properties on pavement structures [75-77].

For traffic, the state of practice is to model loading as static forces. Tire-pavement contact area is simplified as uniform distributed stress on a circular area. It was found that using uniform contact stresses could underestimate pavement damage than using 3-D tire contact stress [78]. The implementation of dynamic and moving loading on pavement structural analysis is also necessary. Moreover, how to model the interface between different layers is another challenge. Only full friction or no friction is available in current models. The application of tack coat and prime coat, which are intended to increase interface bonding, is not considered. Researchers are making progress on this issue, such as the fracture-based elastoplastic constitutive relationship developed by Ozer, Al-Qadi and Leng [79]; but more efforts are desirable to adopt such research into practical applications.

\subsection{Reliability}

Reliability was first introduced to pavement design in AASHTO 1986 Guide, which added two new variables into the design equation: standard deviate $Z_{R}$ and standard error $S_{0}$. This concept was continuously adopted in AASHTO 1993 Guide and MEPDG. In general, it is a congregated reliability that contains all sources of uncertainty. The assumption is that the difference between predicted and measured pavement performance come from all uncertainties. Therefore, the current reliability model cannot consider any specific uncertainty from individual parameters. For example, inputs in Level 1 use the same reliability model with them in Level 3, although the hierarchal input assumes that Level 1 would have lower level of uncertainty than Level 3 [1]. In addition, the current MEPDG applies the same reliability model, nationally calibrated from LTPP database, on all states. Apparently the difference of construction techniques, specifications and quality control from state to state is not considered by this method.

There are three barriers towards a comprehensive reliability model. One is that MEPDG has hundreds of variables. The second is that MEPDG is not an explicit mathematic equation but a combination of mechanistic models and transfer functions. The third is that MEPDG takes a lot of computing time and resource, especially for flexible pavement design. It is due to the extensive computing time that Monte Carlo Simulation (MCS), by far the most accurate probability technique available, could not be applied on MEPDG.

Retherford and McDonald [80] evaluated the suitability some other reliability techniques such as the mean value first-order second moment (MVFOSM), first-order reliability methods (FORMs), Rosenblueth, and advanced mean value (AMV) for mechanistical empirical pavement design. The research concluded that these methods, in particular the AMV method, can be used efficiently to perform component and system reliability analysis. It was also noted that probabilistic methods should be included in MEPDG in a manner accessible to practicing engineers without backgrounds in probabilistic methods and allow the MEPDG to assure reliability while still requiring only deterministic inputs to the analysis.

\subsection{Incorporating pavement preservation}

Pavement preservation provides a means for maintaining and improving the functional condition of an existing highway system and slowing deterioration. Although pavement preservation is not expected to subsstantially increase structural capacity, it generally leads to improved pavement performance and longer service 
life and, therefore, should be considered in the pavement design process. However, the MEPDG procedure and related performance prediction models focus on new design and structural rehabilitation and do not explicitly consider the contributions of pavement preservation treatments to the overall pavement performance. There is a need to identify approaches for considering the effects of preservation on pavement performance and to develop procedures that facilitate consideration of pavement preservation treatments in the MEPDG analysis process. Currently the NCHRP $01-48$ project [81] is active to achieve this goal.

\section{Conclusions}

The Mechanistic-Empirical Pavement Design Guide represents a major change in the way pavement design is performed. The MEPDG changes not only the design process and inputs but the way that engineers develop and implement effective and efficient pavement design. Implementation of the MEPDG design process therefore demands that the designers be knowledgeable about pavement design inputs and pavement performance. In addition, interaction is necessary among the highway agency engineers who work in traffic, materials, geotechnical areas, and pavement structures to identify the proper input parameters for the design. This paper, for the first time, provides a comprehensive synopsis of the various challenges and achievements during the phases of the development, improvement, and implementation of the MEPDG procedure. Based on the overview of the design procedure and the research been conducted, challenges remained and future research directions are identified, including a robust sensitivity analysis of the inputs, enhancement of climatic models, the impacts of potential climate change, traffic data quality control, local calibration and new materials. At the same time, the limitations of the mechanistic models, the reliability concepts in MEPDG, and the challenges to incorporate preservation into the design procedure are also addressed which require future research.

\section{Disclaimer}

The views expressed in this paper and the accuracy of the data and facts contained herein are the sole responsibility of the authors, and do not necessarily represent the official views of the listed agencies. This paper does not constitute a standard, specification, or regulation. Comments contained in this paper related to specific testing equipment should not be considered an endorsement of any commercial product or service; no such endorsement is intended or implied.

\section{References}

[1] ARA Inc., Guide for mechanistic-empirical design of new and rehabilitated pavement structures, Champaign, 2004.

[2] AASHTO, Guide for design of pavement structures, Washington D.C.: American Association of State Highway and Transportation Officials, 1993.

[3] Federal Highway Administration (FHWA), Status of pavement design in the US, http://www.fhwa.dot.gov/pavement/dgit/dgitsurv.cfm, 2011-04-01.

[4] Thompson, Calibrated mechanistic structural analysis procedures for pavements, Urbana-Champaign: University of Illinois Construction Technology Laboratories, 1990.

[5] WSDOT Pavement Guide, http://training.ce.washington.edu/WSDOT/, 2011-04-01.

[6] MnPave Home, http://www.dot.state.mn.us/app/mnpave/ index.html, 2011-04-01.

[7] Federal Highway Administration (FHWA), Long-term pavement performance program highlights: accomplishments and benefits 1989-2009, McLean: TurnerFairbank Highway Research Center, 2010.

[8] C.S. Desai, User's Manual for the DSC-2D Code for the 2002 Design Guide, Phoenix: Arizona State University, 2001.

[9] L. Khazanovich, H.T. Yu, S. Rao, et al, ISLAB2000finite element analysis program for rigid and composite pavements, user's guide, Champaign: ERES Division of ARA, Inc., 2000.

[10] K.D. Hall, S. Beam, Estimating the sensitivity of design input variables for rigid pavement analysis with a mechanistic-empirical design guide, Transportation Research Record: Journal of the Transportation Research Board, 2005(1919): 65-73.

[11] B. Coree, H. Ceylan, D. Harrington, Implementing the mechanistic-empirical pavement design guide, Ames: Iowa State University, 2005.

[12] R.C. Graves, K.C. Mahboub, Part 2: flexible pavements: pilot study in sampling-based sensitivity analysis of NCHRP design guide for flexible pavements, Transportation Research Record: Journal of the Transportation Research Board, 2006(1947): 123-135.

[13] V. Kannekanti, J. Harvey, Sensitivity analysis of 2002 design guide distress prediction models for jointed plain concrete pavement, Transportation Research Record: Journal of the Transportation Research Board, 2006(1947): 91-100.

[14] R.W. Sauber, N.P. Vitillo, S. Zaghloul, et al, Sensitivity analysis of input traffic levels on mechanistic-empirical design guide predictions, In: the 84th Transportation Research Board Annual Meeting, Washington D.C.: National Research Council, 2006.

[15] T. Freeman, J. Uzan, D. Zollinger, et al, Sensitivity analysis and strategic plan development for the implementation of the M-E design guide in TxDOT operation, College Station: Texas Transportation Institute, 2006.

[16] M.W. Witczak, A. Solti, Project report-NCHRP project 9-19: a recommended methodology for developing dynamic modulus $E^{*}$ master curves from non-linear opti- 
mization, Tempe: Arizona State University, 2004.

[17] N.H. Tran, K.D. Hall, Evaluation of testing protocols for dynamic modulus of hot-mix asphalt, Transportation Research Record: Journal of the Transportation Research Board, 2006(1970): 126-132.

[18] B. Birgisson, G. Sholar, R. Roque, Evaluation of a predicted dynamic modulus for Florida mixtures, Transportation Research Record: Journal of the Transportation Research Board, 2005(1929): 200-207.

[19] N.H. Tran, K.D. Hall, ACHM mix stiffness and static creep behavior, Fayetteville: University of Arkansas, 2005.

[20] K.D. Hall, M. James, PCC materials input values for mechanistic empirical pavement design guide, Fayetteville: University of Arkansas, 2007.

[21] J. Mallela, A. Abbas, T. Harman, et al, Measurement and significance of the coefficient of thermal expansion of concrete in rigid pavement design, Transportation Research Record: Journal of the Transportation Research Board, 2005(1919): 38-46.

[22] M. Won, Improvements of testing procedures for concrete coefficient of thermal expansion, Transportation Research Record: Journal of the Transportation Research Board, 2005(1919): 23-28.

[23] E.J. Sellevold, O. Bjontegaard, Coefficient of thermal expansion of cement paste and concrete: mechanisms of moisture interaction, Materials and Structures, 2006, 39(293): 809-815.

[24] N.D. Dennis, R.M. Welcher, J.H. Lawrence, Investigation of the effect of fines on base course performance, Fayetteville: University of Arkansas, 2006.

[25] Y.S. Zhao, D. Normal, Development of a simplified mechanistic-Empirical design procedure for low-volume flexible roads, Transportation Research Record: Journal of the Transportation Research Board, 2007(1987): 130137.

[26] N.D. Dennis, Jr. K. Bennett, Development of testing protocol and correlations for resilient modulus of subgrade soils, Fayetteville: University of Arkansas, 2005.

[27] Z. Sameh, A. Amr, H.A.E. Amir, et al, Investigations of environmental and traffic impacts on mechanistic empirical pavement design guide predictions, Transportation Research Record: Journal of Transportation Research Board, 2006(1967): 148-159.

[28] Q. Li, K.C.P. Wang, K. Hall, Verification of virtual climatic stations in the mechanistic empirical pavement design guide (MEPDG), International Journal of Pavement Research and Technology, 2010, 3(1): 10-15.

[29] L. Johanneck, L. Khazanovich, Comprehensive evaluation of effect of climate in mechanistic-empirical pavement design guide predictions, Transportation Research Record: Journal of Transportation Research Board, 2010(2170): 45-55.

[30] T.M. Breakah, R.C. Williams, D.E. Herzmann, et al, Effects of using accurate climatic conditions for mechanistic-empirical pavement design, Journal of Transportation Engineering, 2011, 137(1): 84-90.

[31] K.C.P. Wang, Q. Li, K.D. Hall, et al, Development of truck loading groups for the mechanistic-empirical pavement design guide (MEPDG), Journal of Transpor- tation Engineering, Accepted in July 2010.

[32] N.H. Tran, K.D. Hall, Development and influence of statewide axle load spectra on flexible pavement performance, Transportation Research Record: Journal of the Transportation Research Board, 2007(2037): 106114.

[33] FHWA, Guide to LTPP traffic data collection and processing, Washington D.C.: Federal Highway Administration, U.S. Department of Transportation, 2001.

[34] S. Li, T. Nantung, Y. Jiang, Assessing issues, technologies, and data needs to meet traffic input requirements by mechanistic-empirical pavement design guideimplementation initiatives, Transportation Research Record: Journal of the Transportation Research Board, 2005(1917): 141-148.

[35] Cambridge Systematic Inc., Traffic data collection, analysis, and forecasting for mechanistic pavement design, Washington D.C.: Transportation Research Board of the National Academies, 2005.

[36] N.H. Tran, K.D. Hall, Development and significance of statewide volume adjustment factors in mechanisticempirical pavement design guide, Transportation Research Record: Journal of the Transportation Research Board, 2007(2037): 97-105.

[37] K.C.P. Wang, Q. Li, Database support for the new mechanistic-empirical pavement design guide (MEPDG), Transportation Research Record: Journal of the Transportation Research Board, 2008(2087): 109-119.

[38] Transportation Pooled Fund Program, Traffic and data preparation for AASHTO MEPDG analysis and design. http://www.pooledfund.org/projectdetails.asp?id=470\&st atus $=4,2011-04-01$.

[39] FHWA, Traffic monitoring guide, Washington D.C.: Federal Highway Administration, U.S. Department of Transportation, 2001.

[40] A.T. Papagiannakis, M. Bracher, N.C. Jackson, Utilizing clustering techniques in estimating traffic data input for pavement design, Journal of Transportation Engineering, 2006, 132(11): 872-879.

[41] J.A. Prozzi, F. Hong, Hierarchical axle load data for mechanistic-empirical design, In: the 84th TRB Annual Meeting, Washington D.C.: National Research Council, 2005.

[42] Q. Lu, J.T. Harvey, Characterization of truck traffic in California for mechanistic-empirical design, Transportation Research Record: Journal of the Transportation Research Board, 2006(1945): 61-72.

[43] Y. Wang, D.E. Hancher, K. Mahboub, Axle load distribution for mechanistic-empirical pavement design, Journal of Transportation Engineering, 2007, 133(8): 469479.

[44] F. Sayyady, J.R. Stone, K.L. Taylor, et al, Using clustering analysis to characterize MEPDG traffic data in North Carolina, In: the 89th TRB Annual Meeting, Washington D.C.: National Research Council, 2010.

[45] H.V. Quintus, M. Darter, J. Mallela, Mechanistic Empirical Pavement Design Guide Flexible Pavement Performance Prediction Models for Montana, Helena: Minnesota Department of Transportation (MnDOT), 2007.

[46] M. Kang, A.M. Teresa, Local calibration for fatigue 
cracking models used in the Mechanistic-empirical pavement design guide, In: Proceedings of the 2007 Mid-Continent Transportation Research Symposium. Ames, 2007.

[47] H.V. Quintus, J. Moulthrop, Mechanistic-empirical pavement design guide flexible pavement performance prediction models, Kalispell: Montana Department of Transportation, 2007.

[48] E. Fernando, J. Oh, D. Ryu, Phase I of MEPDG program implementation in Florida, Tallahassee: Florida Department of Transportation. 2007.

[49] N.R. Muthadi, Y.R. Kim, Local calibration of mechanistic-empirical pavement design guide for flexible pavement design, Transportation Research Record: Journal of the Transportation Research Board, 2008(2087): 131141.

[50] A. Banerjee, J. Aguiar-Moya, J.A. Prozzi, Texas experience using LTPP for calibration of the MEPDG permanent deformation models, Transportation Research Record: Journal of the Transportation Research Board, 2009(2094): 12-20.

[51] R. Velasquez, K. Hoegh, I. Yut, et al., Implementation of the MEPDG for new and rehabilitated pavement structures for design of concrete and asphalt pavements in Minnesota, St. Paul: Minnesota Department of Transportation, 2009.

[52] J. Li, L.M. Pierce, J. Uhlmeyer, Calibration of flexible pavement in mechanistic-empirical pavement design guide for Washington State, Transportation Research Record: Journal of the Transportation Research Board, 2009(2095): 73-83.

[53] J. Mallela, L.T. Glover, M.I. Darter, et al., Guidelines for implementing NCHRP 1-37A M-E design procedures in Ohio: volume 1-summary of findings, implementation plan, and next steps, Columbus: Ohio Department of Transportation. 2009

[54] K.D. Hall, D.X. Xiao, K.C.P Wang, Calibration of MEPDG for flexible pavement design in Arkansas, Transportation Research Record: Journal of the Transportation Research Board, 2011(2095): 73-83.

[55] FHWA, Local low-volume roads and streets, Washington D.C.: Federal Highway Administration, U. S. Department of Transportation, 1992.

[56] K.D. Hall, J.W. Bettis, Development of comprehensive low-volume pavement design procedures, Fayetteville: University of Arkansas, 2000.

[57] Q. Li, D. Xiao, K.D. Hall, Mechanistic-empirical based pavement design catalog for low-volume roads in Arkansas, Journal of Transportation Research Record accepted in October 2010.

[58] G.E. Elkins, P. Schmalzer, T. Thompson, et al., Longterm pavement performance information management system pavement performance database user guide, McLean: Federal Highway Administration, 2003.

[59] Y.R. Kim, B. Underwood, M.S. Far, et al., LTPP computed parameter: dynamic modulus, Washington D.C.: Federal Highway Administration, 2010.

[60] NCHRP 01-47, Sensitivity evaluation of MEPDG perfor mance prediction, http://144.171.11.40/cmsfeed/TRBNet ProjectDisplay.asp?ProjectID=2487, 2011-04-01.
[61] M.R. Thompson, B.J. Dempsey, H. Hill, et al., Characterizing temperature effects for pavement analysis and design, Transportation Research Record: Journal of the Transportation Research Board, 1987(1121): 14-22.

[62] C.E. Zapata, W.N. Houston, Calibration and validation of the enhanced integrated climatic model for pavement design, Washington D.C.: American Association of State Highway and Transportation Officials in cooperation with the Federal Highway Administration, 2008.

[63] NCHRP 9-23A, A national database of subgrade soil water characteristic curves and selected soil properties for use with the MEPDG, Washington D.C.: Transportation Research Board of the National Academies, 2010.

[64] J. Andrey, B. Mills, F.J. Warren, Climate change impacts and adaptation: a Canadian perspective, http://adaptation. nrcan.gc.ca/perspective/index_e.php, 2010-02-02.

[65] M.D. Meyer, Design Standards for U.S. Transportation infrastructure: the implications of climate change, Washington D.C.: Transportation Research Board of the National Academies, 2006.

[66] Transportation Research Board (TRB), Potential impacts of climate change on U.S. transportation, Washington D.C.: National Academies, 2008.

[67] M. Savonis, B. Burkett, J. Potter, Impacts of climate variability and change on transportation systems and infrastructure-gulf coast study, Washington D.C.: U.S. Department of Transportation, 2008.

[68] M. Hallenbeck, S.G. Kim, Summary of truck loading patterns in Washington State, Seattle: Washington State Transportation Center, 1993.

[69] W.O. Tam, H.V. Quintus, Use of long-term pavement performance data to develop traffic defaults in support of mechanistic-empirical pavement design procedures, Transportation Research Record: Journal of the Transportation Research Board, 2003(1855): 176-182.

[70] M.A. Al-Yagout, J. Mahoney, L. Pierce, et al., Improving traffic characterization to enhance pavement design and performance: load spectra development (WA-RD 600.1), Seattle: Washington State Transportation Center, 2005.

[71] M. Hallenbeck, WIM data quality assurance, In: Volume II of the National Traffic Data Acquisition Conference, 1994: 251-266.

[72] H.L.V. Quintus, C. Schwartz, R.H. McCuen, et al., Jackknife testing: an experimental approach to refine model calibration and validation, Washington D.C.: Transportation Research Board of the National Research Council, 2003.

[73] M. Mamlouk, C.E. Zapata, Necessary assessment of use of state pavement management system data in mechanistic-empirical pavement design guide calibration process, Transportation Research Record: Journal of the Transportation Research Board, 2010(2153): 5866.

[74] S.A. Schram, M. Abdelrahman, Integration of mechanistic-empirical pavement design guide distresses with local performance indices, Transportation Research Record: Journal of the Transportation Research Board, 2010(2153): 13-23.

[75] Y.G. Chen, Viscoelastic Modeling of Flexible Pavement 
[Dissertation], Akron: University of Akron, 2009.

[76] E. Tutumluer, D.N. Little, S.H. Kim, Validated model for predicting field performance of aggregate base courses, Transportation Research Record: Journal of the Transportation Research Board, 2003(1837): 41-49.

[77] Y.R. Kim, C. Baek, B.S. Underwood, et al., Application of viscoelastic continuum damage model based finite element analysis to predict the fatigue performance of asphalt pavements, KSCE Journal of Civil Engineering, 2008, 12(2): 109-120.

[78] H. Wang, I.L. Al-Qadi, Combined effect of moving wheel loading and three-dimensional contact stresses on perpetual pavement responses, Transportation Research
Record: Journal of the Transportation Research Board, 2009(2095): 53-61.

[79] H. Ozer, I.L. Al-Qadi, Z. Leng, Fracture-based friction model for pavement interface characterization, Transportation Research Record: Journal of the Transportation Research Board, 2008(2057): 54-63.

[80] J.Q. Retherford, M. McDonald, Reliability methods applicable to mechanistic-empirical pavement design method, Transportation Research Record: Journal of the Transportation Research Board, 2010(2154): 130-137.

[81] NCHRP 01-48. Incorporating pavement preservation into MEPDG, http://144.171.11.40/cmsfeed/TRBNetProject Display.asp?ProjectID=2704, 2011-04-01.

(Editor: Yao ZHOU) 